\title{
Advances in the Treatment of Chronic Insomnia: A Narrative Review of New Nonpharmacologic and Pharmacologic Therapies
}

\author{
Russell Rosenberg' \\ Leslie Citrome (iD ${ }^{2}$ \\ Christopher L Drake (iD) ${ }^{3}$ \\ 'Neurotrials Research, Atlanta, GA, USA; \\ ${ }^{2}$ Department of Psychiatry and \\ Behavioral Sciences, New York Medical \\ College, Valhalla, NY, USA; ${ }^{3}$ Thomas \\ Roth Sleep Disorders and Research \\ Center, Henry Ford Health System, \\ Detroit, MI, USA
}

\begin{abstract}
Chronic insomnia disorder, which affects $6-10 \%$ of the population, is diagnostically characterized by ongoing difficulties with initiating or maintaining sleep occurring at least three times per week, persisting for at least 3 months, and associated with daytime impairment. While chronic insomnia is often considered a condition primarily related to impaired sleep, the disorder can also adversely affect domains of physical and mental health, quality of life, and daytime function, which highlights the importance of treating the multidimensional sleep disorder. Owing to misperceptions about the safety and effectiveness of treatment options, many individuals with insomnia may not seek professional treatment, and alternatively use ineffective home remedies or over-the-counter medications to improve sleep. Some physicians may even believe that insomnia is remediated by simply having the patient "get more sleep". Unfortunately, treatment of insomnia is not always that simple. The disorder's complex underlying pathophysiology warrants consideration of different nonpharmacologic and pharmacologic treatment options. Indeed, recent insights gained from research into the pathophysiology of insomnia have facilitated development of newer treatment approaches with more efficacious outcomes. This narrative review provides a summary of the diagnostic criteria and pathophysiology of insomnia and its subtypes. Further, this review emphasizes new and emerging nonpharmacologic and pharmacologic treatments for chronic insomnia, including recent enhancements in approaches to cognitive behavioral therapy for insomnia (CBT-I) and the new dual orexin receptor antagonist (DORA) pharmacologics. These advances in treatment have expanded the treatment options and are likely to result in improved outcomes in patients with chronic insomnia.
\end{abstract}

Keywords: dual orexin receptor antagonists, cognitive behavioral therapy-insomnia, insomnia subtype, hypnotic

\section{Introduction}

Insomnia disorder is described by the American Academy of Sleep Medicine (AASM) International Classification of Sleep Disorders, Third Edition, as having frequent and persistent difficulty initiating or maintaining sleep that results in general sleep dissatisfaction despite adequate opportunity for sleep. The sleep complaint is also accompanied by distress about poor sleep and/or impairment across various domains of functioning (eg, family, social, vocational, academic). ${ }^{1,2}$ Insomnia is classified as short-term if it persists less than 3 months and chronic if it persists at least 3 months and occurs at least three times per week. ${ }^{1,2}$ Similar essential features of insomnia are described in the American Psychiatric Association (APA) Diagnostic
Correspondence: Russell Rosenberg Neurotrials Research, 5887 Glenridge Drive, Suite 400, Atlanta, GA, 30328, USA

Tel + I 40485 I 9934

Email rrosenberg@neurotrials.com 
and Statistical Manual of Mental Disorders, Fifth Edition and include dissatisfaction with sleep quantity or quality with complaints of difficulty initiating or maintaining sleep. ${ }^{3}$ The sleep disturbance must also cause clinically significant distress or impairments in social, occupational, or other important areas of functioning and may occur independently or during the course of another mental disorder or medical condition. ${ }^{3}$ For many, insomnia becomes a long-term and persistent condition. A recent longitudinal study based on annual survey data demonstrated that $37.5 \%$ of participants with insomnia disorder at baseline continued to report insomnia symptoms through 5 years of follow-up. ${ }^{4}$

The International Classification of Sleep Disorders, Third Edition and Diagnostic and Statistical Manual of Mental Disorders, Fifth Edition also describe several secondary insomnias, which arise from co-occurring primary or causative conditions including mental disorders (eg, major depressive disorder), medical conditions (eg, pain), substance use, or another sleep disorder (eg, breathingrelated sleep disorder). ${ }^{1,3}$ Despite these insomnia subtypes, it is often difficult to differentiate between them clinically due to substantial symptom overlap between primary and secondary insomnia. Additionally, it is often difficult to assign causation to any single factor or establish the precise nature of the relationship between insomnia and a cooccurring condition. ${ }^{3}$ Indeed, insomnia frequently persists despite resolution of other conditions and often requires independent treatment. ${ }^{5,6}$ Some studies have shown that cotreatment of insomnia and co-occurring conditions yield more rapid improvement of both conditions compared with independent treatment of only the co-occurring condition, supporting the treatment of insomnia as an independent condition in patients considered to have the "secondary" condition due to a primary medical or mental cause. ${ }^{7,8}$ Other than the different treatments required for distinctive comorbidities, effective treatments for insomnia generally are the same across "primary" or "secondary" insomnia. ${ }^{1,2,9,10}$ It is important to note, however, that for some of the more recent insomnia treatments (eg, dual orexin receptor antagonists [DORAs]), less is known about their effectiveness in patients with insomnia and comorbidities as these newer agents are relatively new and studies of those that have become commercially available have not yet been conducted to evaluate their efficacy specifically in insomnia patients with co-occurring disorders.

In addition to short-term and chronic classifications, insomnia can also be categorized into subtypes (phenotypes) based on the timing of the sleep difficulty occurrence. ${ }^{1-13}$ The main categories are difficulty falling asleep (sleep-onset insomnia), difficulty staying asleep (sleep-maintenance insomnia), early-morning awakenings coupled with an inability to return to sleep (terminal insomnia), and combined insomnia (more than one of these categories). ${ }^{13,14}$ Additionally, insomnia with objective short sleep duration ( $<6$ hours by polysomnography) has also been identified as an important phenotype. ${ }^{15}$ Identification of a patient's specific insomnia phenotype (eg, sleep-onset versus sleep-maintenance insomnia) may help guide treatment. ${ }^{14}$ It is critically important to recognize the dynamic nature of insomnia, and that the stability of a patient's insomnia symptoms may vary over time. ${ }^{13}$ A 4-month longitudinal study of general practice attenders found that only $17-51 \%$ of the patients reported the same sleep complaint(s) at follow-up. ${ }^{12}$ Similarly, in a large, longitudinal community-based study of individuals with current or lifetime insomnia, approximately $60 \%$ retained the same insomnia symptom phenotype after 1 year; $40 \%$ had a different phenotype. ${ }^{14}$ The demonstration in these studies that many patients have conversion of their insomnia symptoms ${ }^{12,14}$ highlights that ongoing assessment is needed to monitor for potential changes in the presenting insomnia symptoms.

In addition to impairing sleep, insomnia can cause adverse consequences across domains of physical and mental health, quality of life, and daytime function. Certainly, lack of sleep/insomnia is associated with increased risk of premature mortality ${ }^{16}$ and linked to serious somatic and psychiatric conditions, including cardiovascular and cerebrovascular disease, diabetes, hypertension, obesity, depression, and post-traumatic stress disorder. ${ }^{16-24}$ Further, insomnia may not necessarily be ameliorated when comorbidities are otherwise successfully managed. A common example of this is persistent sleep difficulties in a person with major depressive disorder despite the substantial relief of mood symptoms with antidepressant medication. ${ }^{25}$ Insomnia disorder can also have direct adverse effects on mood and behavior, including risk for incident depression and anxiety, ${ }^{26}$ as well as a strong link with suicidal ideation. ${ }^{27}$ Treating insomnia can prevent depression in many "at-risk" individuals not depressed at baseline. ${ }^{28}$

People with chronic insomnia often have more medical problems than those without insomnia. ${ }^{29,30}$ In a large-scale assessment of sleep and health ( $>9000$ elderly individuals), participants with chronic insomnia symptoms and those 
reporting rarely or never feeling rested upon awakening were more likely to have respiratory symptoms, physical disabilities, and depressive symptoms; self-reported poorer health; and used more nonprescription medications than those without sleep symptoms. ${ }^{29}$ Likewise, a retrospective analysis conducted in a community-based population found that adults with insomnia had higher rates of heart disease, high blood pressure, neurologic disease, breathing problems, urinary problems, chronic pain, and gastrointestinal problems. ${ }^{30}$ Moreover, a retrospective analysis found that more individuals with medical problems reported they had symptoms of chronic insomnia compared to those without medical problems, suggesting considerable comorbidity between insomnia and medical disorders. $^{30}$

The consequences of insomnia extend even further in that it can also reduce quality of life (QOL), impair neurocognitive functioning, ${ }^{31}$ and pose economic and public health burdens through increased health care utilization, sick leave, and decreased work productivity. ${ }^{32,33}$ An international cross-sectional survey comparing health-related QOL among sufferers of chronic insomnia with good sleepers found that people with insomnia reported significantly reduced health-related QoL as assessed using the 36-Item Short-Form Health Survey. ${ }^{34,35}$ Likewise, the National Epidemiologic Survey on Alcohol and Related Conditions-III (20122013) found that the annual loss of quality-adjusted lifeyears associated with insomnia was significantly greater than other medical conditions assessed, including arthritis, depression, and hypertension. ${ }^{36}$

In industrialized nations, chronic insomnia disorder is estimated to occur in $5-10 \%$ of the general population, although some studies suggest that the rate is as high as $33 \%$ of the adults. $^{2,37}$ Despite the large percentage, a relatively low proportion consult a health care provider about their sleep. ${ }^{38-40}$ The low consultation rate may be due to limited knowledge among the general population about the safety and availability of insomnia treatments that can be offered by clinicians. Self-treatment with overthe-counter sleep aids, as well as alcohol, is not unusual. ${ }^{41}$ Owing to this low rate of consultation about insomnia, health care providers may not consistently recognize and diagnose the condition, ${ }^{39}$ which likely contributes to undertreatment of insomnia. $^{13,39,42}$

Given the potential negative impact of chronic insomnia on patients, clinicians' knowledge of effective treatment strategies is important. To provide such a resource for clinicians, the authors developed this narrative review to summarize the pathophysiology of insomnia and new developments in non-pharmacologic and pharmacologic interventions.

\section{Pathophysiology of Insomnia}

Several models of insomnia etiology and pathophysiology have been proposed, most of which suggest that both external stressors as well as internal psychologic factors have a role. ${ }^{18}$ For example, the Spielman model of insomnia, also known as the "Three Factor" or "Three P" model, comprises three factors: predisposing, precipitating, and perpetuating. ${ }^{43}$ Predisposing factors are traits that predispose an individual to insomnia such as sleep reactivity, ${ }^{44,45}$ personality traits including the tendency to worry or ruminate, and social factors such as sleep schedule incompatibility between bed partners or social pressures leading to a nonpreferred sleep schedule. ${ }^{45}$ The combination of predisposing factors and precipitating factors (stressors, etc) can lead to the triggering of insomnia. ${ }^{44}$ Chronic insomnia is often maintained by perpetuating factors or behaviors adopted in an attempt to mitigate insomnia symptoms and compensate for sleep deficits, such as going to bed earlier or remaining in bed longer. ${ }^{45}$ These behaviors lead to the dysregulation of sleep homeostasis. ${ }^{45}$ Thus, even after the elimination or improvement in the initial triggering factor, insomnia may persist. ${ }^{46}$

Hyperarousal refers to a state of increased somatic, cognitive, and cortical activation occurring in the central and/or peripheral nervous systems, which often includes both cognitive and emotional processes. ${ }^{47}$ Physiological hyperarousal is associated with short sleep duration in insomnia and activation of both limbs of the stress system (the hypothalamic-pituitary-adrenal axis and the sympathetic system). ${ }^{18}$ Consistent with the concept of hyperarousal being associated with stress, many patients with insomnia have increased secretion of adrenocorticotropic hormone and cortisol compared with healthy individuals. ${ }^{46}$ Although patients with insomnia have overall normal circadian secretory patterns of these hormones, their levels are elevated during the evening and first half of the night, which is consistent with the concept of the bedroom environment being a source of stress and activation in people with insomnia. ${ }^{46,48}$ Patients with insomnia also have higher overall mean sleep metabolic rates (as indicated by overall oxygen use) versus individuals without insomnia. ${ }^{49}$ Similarly, in a functional positron emission tomography study conducted in individuals with and 
without insomnia, patients with insomnia had altered glucose metabolism in the brain during sleep and while awake compared with individuals without insomnia. ${ }^{50}$ This altered metabolism may be related to hyperactivation of arousal mechanisms, which fail to decrease during the wake-to-sleep transition. ${ }^{50}$ This physiological hyperarousal may be related to worry and rumination. Both worry and rumination can also lead to emotional arousal and heightened levels of distress that may activate the stress system, which can contribute to hyperarousal as well as the perpetuation of insomnia. ${ }^{51,52}$ The sleep loss itself may also exacerbate cognitive hyperarousal at night owing to increased wakefulness while lying in bed, which may further exacerbate insomnia and rumination. ${ }^{53}$

Genetic factors also contribute to the regulation of sleep-wake traits, including sleep duration and timing of sleep. ${ }^{47}$ Current evidence suggests that multiple genes related to brain functioning, arousal regulation, and sleepwake processes are associated with insomnia. ${ }^{47}$ The first studies conducted to identify genes potentially involved in insomnia examined the role of circadian genes (eg, CLOCK and the Per genes). ${ }^{47}$ While the overall genetic heritability of insomnia is moderate $(30-40 \%),{ }^{54}$ only small associations with specific polymorphisms (eg, Timeless, Per2, and Per3) have been identified, suggesting other factors are involved. $^{55-58}$ Indeed, the serotonin transporter-linked polymorphic region (5-HTTLPR) within the serotonin transporter (SLC6A4) gene promoter has been implicated as contributing to poor sleep via stress reactivity mechanisms. ${ }^{59}$

Wake/sleep signaling in the brain is driven by two competing sets of brain circuitry: one set of neurotransmitter pathways that promotes sleep and another set that promotes wakefulness. ${ }^{60}$ Transitions between sleep and wake states are dependent on the relative strengths of the two opposing sets of circuits and the end result has been described as akin to a flip-flop switch. ${ }^{60}$ Historically, the most common approach in the pharmacologic treatment of insomnia has been to increase the sleep signal, such as with medications that target the $\gamma$-aminobutyric acid (GABA)-A receptor. However, this may not be the best approach physiologically if the insomnia disorder is due to excessive wake signaling occurring at the time when the individual is expected to fall asleep and remain asleep. Decreasing the excessive wake signal has recently become a viable option for medication treatment now that orexin has been identified as a key central promotor of wakefulness.
The orexin neuropeptide signaling system is involved in several physiological functions, particularly sleep and arousal. ${ }^{61}$ It is one of the primary systems that maintains wakefulness throughout the day and is involved with the regulation of rapid eye movement (REM) sleep. ${ }^{61,62}$ Two neuropeptides, orexin-A (OXA) and orexin-B (OX-B), both derived from the common precursor prepro-orexin, activate two postsynaptically localized $\mathrm{G}$ protein-coupled receptors, orexin receptor type 1 (OX1R) and orexin receptor type 2 (OX2R). ${ }^{61}$ OX1R predominantly interacts with OX-A, whereas OX2R interacts with OX-A and OX-B with similarly high affinity. ${ }^{63}$ Activation of $\mathrm{OX} 1 \mathrm{R}$ and OX2R suppresses the onset of REM sleep and activation of OX2R suppresses non-REM sleep. ${ }^{64}$ If orexin binding to either of its receptors causes arousal (wakefulness), then a substance that acts as an antagonist of OX1R and/or OX2R for an extended period of time can promote sleep by inhibiting the wake-promotion associated with the orexin signaling pathway. ${ }^{65,66}$

\section{Nonpharmacologic Treatments for Chronic Insomnia}

As regards behavioral and psychological treatments for chronic insomnia, clinical practice guidelines from the AASM and the American College of Physicians (ACP) both indicate that standard-of-care should be to at least provide cognitive behavioral therapies for insomnia (CBTI) as first-line nonpharmacologic treatment. ${ }^{9,67}$ Indeed, CBT$\mathrm{I}$ is the only nonpharmacologic treatment for chronic insomnia that has received a strong recommendation for use by the AASM. ${ }^{9}$ This is likely due in part by the numerous metaanalyses demonstrating robust clinical improvements across numerous sleep-related outcomes using individual, group, internet-based, and self-help CBT-I. ${ }^{68}$

Other nonpharmacologic treatments for the treatment of chronic insomnia have been described in AASM guidelines. Brief therapies for insomnia, stimulus control, sleep restriction therapy, and relaxation therapy, and sleep hygiene (Table 1) are all included as potential treatment options. ${ }^{9}$ However, guidelines acknowledge that usefulness as a treatment for chronic insomnia is often based on a small body of low-quality evidence. ${ }^{9}$ Further, their uses (except for sleep hygiene) are mostly indicated as single-component therapy. 
Table I Selected Elements of Good Sleep Hygiene ${ }^{155,156}$

Element
- Keeping a regular sleep/wake schedule
- Reducing bedroom noise
- Blocking out light
- Removing electronic devices from the bedroom
- Avoiding daytime napping
- Avoiding alcohol, nicotine, and caffeine before sleeping
- Avoiding eating dinner late
- Regular exercise
- Management of stress

\section{CBT-I}

CBT-I includes a combination of behavioral interventions: stimulus control therapy to pair the bed with sleep, sleep restriction/compression to increase sleep pressure, relaxation training to reduce hyperarousal, specific cognitive interventions aimed at changing patients' beliefs and attitudes about sleep, and sleep hygiene education. ${ }^{69,70}$ Cognitive strategies (such as cognitive restructuring to identify and address dysfunctional beliefs and unrealistic expectations that can perpetuate insomnia) are used as part of CBT-I to break a cycle that can lead to, maintain, or worsen insomnia. ${ }^{71}$ Although cognitive therapy and behavioral therapy alone are effective, patients derive the most benefit when all components of CBT-I are combined with an eight-week course of treatment. ${ }^{69,72}$ It should be noted that CBT-I may be contraindicated in some patients. Sleep loss through sleep restriction in CBT-I may exacerbate comorbidities including seizure disorders, severe obstructive sleep apnea, and untreated bipolar disorder, in individuals who are actively suicidal, or in patients with severe parasomnias. $^{73-75}$

However, not all patients with insomnia disorder may receive sufficient benefit from CBT-I., ${ }^{2,10}$ Indeed, only approximately $30-40 \%$ of the patients undergoing CBT-I reach remission. ${ }^{76-79}$ This may be due to the time commitments, the work involved to change sleep habits and schedules, and highly engrained maladaptive beliefs about sleep. ${ }^{2,80}$ Also, an important consideration for CBT-I is that some behavioral treatments may be more appropriate for specific insomnia phenotypes. ${ }^{14}$ For example, relaxation may be more useful for sleep onset insomnia, whereas sleep restriction, which increases the pressure for sleep so that sleep inevitably occurs without attention, intention, or effort, may benefit both sleep onset and sleep maintenance insomnia. ${ }^{14,81}$ At times, the typical CBT-I approach may have limited usefulness because there are too few sessions to address the engrained ways of thinking about and interpreting one's own sleep. This can result in the CBT-I not having a powerful enough effect on the cognitive arousal that occurs at night to provide full remission.

As a caveat, some individuals may have persistent maladaptive beliefs. In an assessment of the effects of CBT-I on sleep-related dysfunctional beliefs, a significant correlation was found between the Athens Insomnia Scale and the Dysfunctional Beliefs and Attitudes About Sleep Scale at baseline and improvements occurred on both scales following CBT-I. ${ }^{82}$ However, the decrease in dysfunctional beliefs and attitudes about sleep was not related to improvements in or decreased severity of insomnia. ${ }^{82}$

Several barriers prevent CBT-I from being more widely used in clinical practice. ${ }^{80}$ Not all patients are able to gain access to CBT-I because of a lack of availability of providers or cost constraints. ${ }^{2,80}$ In addition, CBT-I requires patients to make a considerable time commitment that they may be unable or unwilling to do. CBT-I also requires a substantial time investment of trained clinicians, which means demand for CBT-I providers often exceeds supply. ${ }^{80,83}$ Both health care practitioners and patients may lack sufficient knowledge about CBT-I and its effectiveness. ${ }^{80}$ Many health care practitioners do not refer their patients for treatment with CBT-I alone, despite CBT-I being a first-line treatment. ${ }^{84}$ A 2015 survey of physicians found that a majority considered medications and other treatment options to be more effective than CBT-I alone. ${ }^{84}$ Thus, more clinician education about CBT-I is necessary and new approaches to its delivery are needed. ${ }^{84}$

A way to increase access to CBT-I is through "stepped care," which is a sequential approach to care management that manages high patient volume via low-intensity treatments initially and progressively moves to more intense treatment based on assessed need. ${ }^{85}$ The initial therapeutic approach should be the least restrictive therapy, readily accessible, the lowest cost, and least inconvenient for patients. ${ }^{85}$ For insomnia treatment, the entry-level treatment would be self-administered CBT-I with more specialized types of CBT-I, such as manualized, small-group CBT-I delivered by nurses, and eventually sleep specialists, including psychologists, at higher levels. ${ }^{85}$

Providing CBT-I via the internet (digital CBT-I) is another possible solution to reduce the time investment and increase accessibility. ${ }^{83}$ In a randomized controlled trial comparing six guided online CBT-I sessions to six face-to-face CBT-I sessions or wait-listing potential 
participants meeting the Diagnostic and Statistical Manual of Mental Disorders, Fifth Edition criteria for insomnia, both face-to-face and online interventions had significantly larger treatment effects than the wait-list group. ${ }^{83}$ The face-to-face treatment yielded a statistically greater treatment effect than the online sessions; however, some improvements were also seen with online CBT-I, suggesting that digital delivery of CBT-I may provide an alternative and/or companion to face-to-face treatment. ${ }^{83}$ In addition, in a recent meta-analysis of randomized clinical trials comparing digital CBT-I to controls, digital CBT-I significantly reduced insomnia severity and was noninferior to face-to-face delivery. ${ }^{86}$ In fact, digital CBT-I not only improves insomnia but it also has robust and longlasting effects on improving and preventing depression in patients with insomnia disorder. ${ }^{28}$

Another new technology useful for facilitating CBT-I is the use of a smartphone application (app) such as CBT-I Coach. CBT-I Coach is a patient-facing app from the US Department of Veterans Affairs, Stanford University's School of Medicine, and the US Department of Defense National Center for Telehealth and Technology designed to enhance CBT-I. ${ }^{87}$ CBT-I Coach is intended for use by patients undergoing CBT-I with a health care professional to act as an educational resource to support, but not replace, the clinician-delivered CBT-I. ${ }^{87}$ The app provides automated sleep diary calculations, sleep education, tools to practice CBT-I skills, and reminders to complete sleep diaries and follow recommendations for time in bed. ${ }^{87}$ These reminders have the potential to reduce treatment dropout and address common adherence issues and, therefore, may improve insomnia outcomes. ${ }^{87}$ Surveys of US Department of Veterans Affairs physicians trained in delivering CBT-I regarding their perceptions of CBT-I Coach 2 years after its launch demonstrated that almost $60 \%$ of the clinicians were using the app with their patients and had a favorable view of its utility in improving CBT-I outcomes. $^{87}$

A newer approach to CBT-I therapy itself is to employ a combination of mindfulness-based stress reduction with CBT-I. ${ }^{88}$ This combination approach, which is sometimes called mindfulness-based therapy for insomnia (MBTI), ${ }^{89}$ results in statistically significant and clinically meaningful improvements in multiple nighttime symptoms of insomnia. In addition, significant reductions in presleep arousal, sleep effort, and dysfunctional sleep-related cognitions were observed. ${ }^{88}$ This may be due, in part, to the fact that MBTI was designed to address rumination. ${ }^{52}$ In an assessment of the long-term effects of the MBTI approach, the benefits of this combined approach on insomnia and symptom severity were generally maintained during the 12-month follow-up. ${ }^{90}$ Use of one or more of these newer approaches to CBT-I, such as digital CBT-I and/or MBTI, may be critical to increase the response of patients to nonpharmacologic treatments for insomnia.

Other new methods of behavioral treatment include CBT-I for specific populations. For example, owing to hormonal, anatomic, and physiological changes, pregnant women tend to experience sleep disturbances and insomnia more frequently than the general population. ${ }^{91}$ Since patients and prescribers are likely to have concerns about the use of sleep medication in women who are pregnant or breastfeeding, CBT-I may be a more appropriate and preferred intervention for insomnia during pregnancy and the postpartum period. ${ }^{91,92}$ In a randomized, unmasked, controlled trial comparing CBT-I to control insomnia therapy (modified pseudodesensitization therapy for insomnia) in women with insomnia disorder between 18 and 32 weeks of pregnancy, CBT-I was associated with significantly faster remission of insomnia. In addition, significantly greater improvements in insomnia severity, total wake time, and Edinburgh Postnatal Depression Scale scores versus control therapy $(p<0.01$ for all $)$ were also observed. $^{93}$ More women treated with CBT-I attained remission of insomnia than with control therapy with a favorable effect size. ${ }^{93,94}$

Similarly, the hormonal fluctuations associated with menopause mean that postmenopausal women also experience insomnia at higher rates than the general population. ${ }^{91}$ In a clinical trial comparing CBT-I to sleep restriction therapy and sleep hygiene education to treat insomnia in postmenopausal women, CBT-I was associated with greater improvement in Insomnia Severity Index scores, increased improvement in sleep duration, and greater remission rates than sleep restriction therapy or sleep hygiene education. ${ }^{95}$ In addition, both CBT-I and sleep restriction therapy improved fatigue, energy, sleepiness, and work function. ${ }^{96}$ Whereas sleep restriction therapy and sleep hygiene education improved resilience to physical problems, CBT-I was associated with substantial improvements in emotional well-being and resilience to both physical and emotional problems. ${ }^{96}$ CBT-I also reduced depressive symptoms, dysfunctional beliefs about sleep, and presleep somatic hyperarousal in 
postmenopausal women more than sleep restriction therapy and sleep hygiene education. ${ }^{97}$

\section{Forehead Temperature Cooling}

An alternative nonpharmacologic approach to treating insomnia is to reduce the increased activity and frontal cerebral metabolism that occurs during hyperarousal in patients with insomnia by application of a cooling stimulus to the scalp. ${ }^{98}$ Application of a novel forehead temperature regulating device that can be adjusted to deliver frontal cerebral thermal therapy ranging from $14^{\circ} \mathrm{C}$ to $16^{\circ} \mathrm{C}(57-$ $61^{\circ} \mathrm{F}$ ) produced improvements in latency to persistent sleep, latency to stage 1 non-REM sleep, latency to stage 2 non-REM sleep, and an increase in the number of minutes of sleep during the first hour of sleep with a trend to reduce latency to stage 3 non-REM sleep. These improvements were observed in men and women with primary insomnia (defined per Diagnostic and Statistical Manual of Mental Disorders, Fourth Edition) without major syndromal mood, anxiety, psychotic, substance use or current sleep disorders other than insomnia. ${ }^{98}$ Similar improvements in insomnia, as well as improvements in anxiety and depressive symptoms, were observed when a forehead cooling device was studied in veterans with chronic insomnia disorder and comorbid medical and psychiatric conditions. ${ }^{99}$ These results suggest that this device could be useful for patients who prefer nonpharmacologic methods of treating insomnia, but are unable to use CBT-I, or as adjunctive therapy for other treatments although the long-term efficacy and safety of this approach needs to be evaluated. ${ }^{98,99}$

\section{Pharmacologic Treatments for Chronic Insomnia Treatment Guidelines and Recommendations for Pharmacologic Treatments}

Not all patients with chronic insomnia disorder benefit from CBT-I alone or have access to this modality. ${ }^{2}$ Treatment guidelines from both the APA and the ACP recommend health care practitioners use a shared decisionmaking approach with patients when considering whether to use or add pharmacologic therapy., ${ }^{2,67}$ This approach should include a discussion of the benefits, risks, and costs associated with the use of medications. ${ }^{67}$

The pharmacologic therapies listed in the treatment guidelines from the ACP include those medications approved by the US Food and Drug Administration (FDA) for treatment of insomnia, such as benzodiazepines (BZDs) and the non-BZD hypnotic "Z-drugs", the DORAs suvorexant, the melatonin receptor agonist ramelteon, and the first-generation histamine antagonist doxepin, as well as off-label use of other agents. ${ }^{67}$ However, these guidelines note that there was insufficient evidence to determine the efficacy or the benefit:risk ratio of many of these therapies, and therefore the guidelines do not make any specific recommendations for any single medication. ${ }^{67}$

Similarly, the AASM makes suggestions about whether specific pharmacologic therapies should be used for the treatment of sleep onset and/or sleep maintenance insomnia. ${ }^{2}$ Several medications including different BZD receptor agonists and BZDs are recommended for treating both insomnia subtypes. ${ }^{2}$ Therapies recommended specifically for use in sleep onset insomnia include the BZD receptor agonist zaleplon, the BZD triazolam, and the melatonin agonist ramelteon, whereas recommended therapies for sleep maintenance insomnia include suvorexant and doxepin. ${ }^{2}$ However, trazodone, the anticonvulsant tiagabine, and over-the-counter medications such as diphenhydramine, melatonin, L-tryptophan, or valerian are not recommended for treating either type of insomnia. ${ }^{2}$ All of the specific recommendations by the AASM are classified as "weak" because they are based on the degree of confidence in the availability of efficacy data, quality of efficacy data, and other considerations, including potential risks and patient preferences. $^{2}$ The weak classification of these recommendations should not be misinterpreted as meaning that sleep-promoting medications are not efficacious or indicated for insomnia treatment, just that the existing data limit the degree of confidence in these recommendations. $^{2}$

It is important to note that the most recent ACP and AASM guidelines predate the approval of the DORA lemborexant, which was approved in the United States in December 2019, in Japan in January 2020, and in Canada in November $2020 .^{100,101}$

In addition, the 2019 American Geriatrics Society Beers Criteria for Potentially Inappropriate Medication Use in Older Adults indicate that older adults should avoid BZDs and non-BZD hypnotic "Z-drugs" because of increased sensitivity to these medications and the increased risk of cognitive impairment, delirium, falls, fractures, and motor vehicle accidents. ${ }^{102}$ Older patients 
should also avoid doxepin doses $>6 \mathrm{mg}$ owing to the potential for orthostatic hypotension. ${ }^{102}$

\section{Pharmacologic Agents Used for Treating Insomnia}

Historically, pharmacologic agents such as opioids, herbal preparations, barbiturates, alcohol, and pain medications have been used to treat insomnia or to manage sleep disturbances. ${ }^{2,38,39}$ Whereas alcohol can act as a sedative, intake of large amounts of alcohol prior to sleep can cause changes in sleep architecture and disrupted, poor-quality sleep, which can contribute to insomnia. ${ }^{103}$ Many of the other early therapies were effective, but they were associated with next-day residual effects, development of physiological tolerance, and dependence, adverse effects following long-term use, withdrawal effects, and concerns regarding abuse and misuse. ${ }^{2,13}$ In addition, health care practitioners often cite concerns about safety and dependency as key reasons why they hesitate to treat insomnia with medications, particularly BZDs and the non-BZD hypnotics. $^{2}$

\section{Hypnotics}

Clinical trials of hypnotic medications often select participants based on their specific insomnia phenotypes, which could affect the indications and labeling of these agents based on whether they affect sleep onset difficulties, sleep maintenance problems, or both. ${ }^{14}$ The AASM treatment guidelines for insomnia also make similar distinctions regarding the use of pharmacologic agents. ${ }^{2,14}$ For example, the BZD receptor agonists zolpidem and zaleplon are often prescribed for patients with sleep onset insomnia because they are fast acting and have relatively short halflives. ${ }^{13,104}$ In addition, unlike BZDs (which reduce stage 3 and 4 sleep), non-BZD receptor agonists do not consistently alter sleep architecture, although high doses may reduce REM sleep. ${ }^{105}$ However, the short half-life of these agents may not be as effective for sleep maintenance problems, ${ }^{13}$ although zolpidem is also available as an extended-release formulation, which has demonstrated efficacy on sleep onset and sleep maintenance outcomes. $^{106}$

GABA is the main inhibitory transmitter in the mammalian brain and works through GABA-A and GABA-B receptors. ${ }^{107}$ BZDs and non-BZD hypnotics act as positive allosteric modulators on GABA-A receptors, which are widespread throughout the brain, to enhance the action of GABA and cause sedation by prolonging the duration of inhibitory postsynaptic currents. ${ }^{107}$ This increase in GABA transmission has an inhibitory effect on norepinephrine transmission through wake-promoting pathways, which causes sedation and inhibition of wake-promoting regions of the brain, thereby promoting sleep. ${ }^{108}$

As discussed, stability of a patient's insomnia symptoms may vary over time. ${ }^{12-14}$ Whereas follow-up and reassessment of the presenting pattern of insomnia should be conducted regularly, ${ }^{104}$ using agents with effects on both sleep initiation and maintenance could address the lack of stability in these temporal insomnia phenotypes. This could also minimize the need for patients to switch medications if their symptoms change over time.

An optimal pharmacologic treatment for insomnia should not only improve sleep maintenance, sleep onset, sleep quality, and daytime functioning, but also be safe and effective for long-term use without next-day residual effects or symptoms of tolerance, rebound, or dependence. ${ }^{13}$ The treatment should also normalize sleep architecture by reducing sleep onset latency (SOL), wake after sleep onset (WASO), awakenings, arousals, and frequency and duration of wake episodes, as well as maintaining normal sleep stage amounts and distribution. Some of the medication therapies mentioned in treatment guidelines may have limited efficacy in treating all phenotypes of insomnia and/or they may be limited by safety and tolerability concerns. For example, whereas specific BZDs are indicated for treating patients with sleep onset insomnia, sleep maintenance insomnia, or both sleep onset and sleep maintenance insomnia, this class of agents can cause next-day sedation and cognitive impairment, and is associated with an increased risk for abuse and dependence. ${ }^{13}$ In addition, in 2019, the FDA added boxed warnings about the possibility of complex sleep behaviors, such as sleepwalking and sleep driving, to prescribing information and patient medication guides for eszopiclone, zaleplon, and zolpidem. ${ }^{109}$ Thus, formation of a pharmacologic treatment plan is directed by several factors including perhaps most prominently, symptom pattern (eg, difficulty with sleep onset vs sleep maintenance), as well as treatment efficacy (eg, reduced SOL vs WASO) and side effects. ${ }^{10}$

\section{Dual Orexin Receptor Antagonists: A New Class of} Pharmacologic Treatment for Insomnia

The DORAs block OX1R and OX2R and promote sleep through a decrease in arousal signaling, which, as has been noted, is a different therapeutic approach for insomnia. ${ }^{65,66,110,111}$ Several DORAs have been evaluated 
for the treatment of insomnia preclinically and in clinical trials, with two DORAs currently approved for use (Table 2). ${ }^{66,100,101,112}$ Of note, orexin receptor antagonists do not adversely affect sleep architecture. ${ }^{113,114}$ They have been found to shorten REM latency and increase total sleep time (TST), mainly by increasing the time spent in REM sleep. ${ }^{113-}$ ${ }^{115}$ However the percentage of TST spent in non-REM sleep is left unchanged or possibly lowered. ${ }^{113-115}$ They do not appear to be associated with tolerance, withdrawal, or rebound insomnia if abruptly discontinued. ${ }^{116-118}$ Importantly, the mechanism of action of DORAs suggests that daytime sleepiness would be further exacerbated in patients with narcolepsy (as they already have impaired orexin-mediated wake signaling). ${ }^{119-121}$ Accordingly, DORAs are contraindicated in these patients.

After its initial approval in Japan, ${ }^{112}$ suvorexant was the first DORA to receive approval in the United States, where it is indicated for the treatment of insomnia characterized by difficulties with sleep onset and/or sleep maintenance. ${ }^{122}$ Suvorexant has received subsequent approvals in Australia and Canada. ${ }^{123,124}$ The efficacy and safety of suvorexant were evaluated in two randomized double-blind, placebocontrolled, parallel-group Phase 3 clinical trials conducted for 3 months, as well as in one randomized, placebocontrolled, parallel-group phase 3 clinical trial conducted for 1 year. $^{116,117}$ In both the 3-month trials, the higher dose, suvorexant 40/30 mg (40 mg in patients 18-64 years of age and $30 \mathrm{mg}$ in patients $\geq 65$ years of age; not approved), demonstrated superiority versus placebo in improving patientreported subjective TST (sTST), subjective time to sleep onset (sTSO), subjective WASO (sWASO) and polysomnography (PSG)-measured wakefulness after persistent sleep onset when assessed at 1 week, 1 month, and 3 months. ${ }^{116}$ Suvorexant $40 / 30 \mathrm{mg}$ also demonstrated superiority versus placebo in improving PSG-based latency to onset of persistent sleep (LPS) in both trials when assessed at 1 week and 1 month, but in only one trial when assessed at 3 months. ${ }^{116}$ The lower dose (suvorexant 20/15 mg; 20 mg in patients 1864 years of age and $15 \mathrm{mg}$ in patients $\geq 65$ years of age) was superior to placebo on sTST and wakefulness after persistent sleep onset at all study time points, and on sTSO and LPS for most time points. ${ }^{116}$ In the 1-year trial, suvorexant $40 / 30 \mathrm{mg}$ significantly improved sTST and sTSO over the first month of treatment versus placebo. ${ }^{117}$ However, long-term data on approved doses of suvorexant are not available. Significant improvements with suvorexant 40/30 mg versus placebo were also observed for sWASO at 1 month, and for sTST, sTSO, and sWASO at 12 months. ${ }^{117}$ Additionally, in a four-week, double-blind, placebo-controlled study in 285 patients with mild to moderate Alzheimer's disease, suvorexant (10$20 \mathrm{mg}$ ) improved TST as determined by PSG. ${ }^{125}$

Suvorexant was well tolerated in the phase 3 clinical trials with low rates of patients discontinuing because of adverse events or experiencing serious adverse

Table 2 Orexin Receptor Antagonists Approved or in Development for Treatment of Insomnia Disorder

\begin{tabular}{|c|c|c|c|c|}
\hline Name & $\begin{array}{l}\text { Development } \\
\text { Status }\end{array}$ & Doses & Half-Life & Use in Special Populations \\
\hline $\begin{array}{l}\text { Suvorexant } \\
\left(\text { BELSOMRA }^{\circledR}\right)^{122}\end{array}$ & Approved & $\begin{array}{l}5 \mathrm{mg}, \\
10 \mathrm{mg}, \\
15 \mathrm{mg} \\
20 \mathrm{mg}\end{array}$ & $\begin{array}{l}\text { Terminal half-life: approximately } 15 \text { hours } \\
\text { (range, 10-22 hours) }\end{array}$ & $\begin{array}{l}\text { - Not recommended in patients with } \\
\text { severe hepatic impairment } \\
\text { - Safety and effectiveness have not been } \\
\text { established in pediatric patients }\end{array}$ \\
\hline $\begin{array}{l}\text { Lemborexant } \\
\left({ }_{(D A Y V I G O}\right)^{131}\end{array}$ & Approved & $5 \mathrm{mg}, 10 \mathrm{mg}$ & $\begin{array}{l}\text { Effective half-life for lemborexant } 5 \mathrm{mg}: 17 \\
\text { hours; effective half-life for lemborexant } 10 \mathrm{mg} \text { : } \\
19 \text { hours }\end{array}$ & $\begin{array}{l}\text { - Not recommended in patients with } \\
\text { severe hepatic impairment } \\
\text { - Safety and effectiveness have not been } \\
\text { established in pediatric patients }\end{array}$ \\
\hline Daridorexant $^{157}$ & $\begin{array}{l}\text { Filing in } \\
\text { preparation }\end{array}$ & $\begin{array}{l}10 \mathrm{mg} \\
25 \mathrm{mg} \\
50 \mathrm{mg}^{145,146}\end{array}$ & Elimination half-life: $5.6-8.5$ hours $^{158}$ & - Prescribing information not available \\
\hline Seltorexant ${ }^{149}$ & Phase 3 & $20 \mathrm{mg}$ & Half-life: $2-3$ hours ${ }^{149}$ & $\begin{array}{l}\text { - Under development for use in patients } \\
\text { with major depressive disorder and } \\
\text { insomnia } \\
\text { - Prescribing information not available }\end{array}$ \\
\hline
\end{tabular}


events. $^{116,117}$ Incidences of rebound insomnia, nextmorning effects, and withdrawal signs or symptoms were low in the clinical trials. ${ }^{116,117}$ Similar results were reported in a pooled analysis of the 3-month data from the three phase 3 clinical trials. ${ }^{126}$ Overall benefit-to-risk ratio for suvorexant treatment is favorable, as measured by number needed to treat, number needed to harm, and likelihood to be helped or harmed. ${ }^{127}$

Suvorexant was also assessed in patients with mild to moderate obstructive sleep apnea (OSA). ${ }^{128}$ This is of interest because some current insomnia medications, such as BZDs, are associated with respiratory depression, which raises safety concerns, particularly in individuals with compromised respiratory function, such as those with OSA. In this randomized, double-blind, placebocontrolled, crossover study, suvorexant $40 \mathrm{mg}$ (twice the 20-mg maximum approved dose) did not appear to affect respiratory safety during sleep. ${ }^{128}$

In two clinical studies evaluating performance of nextmorning driving by using a 1-hour standardized highway driving test in normal traffic conducted 9 hours after dosing in healthy volunteers $23-64$ or $65-80$ years of age, no clinically meaningful residual effects of suvorexant on driving performance were found versus placebo. ${ }^{129,130}$ However, the authors noted that some individuals experienced somnolence and prematurely stopped their driving tests. ${ }^{129,130}$ Because of concerns related to sleep paralysis, hypnagogic hallucinations, cataplexy, and suicidal ideation, the FDA only approved lower doses of suvorexant $(5,10,15$, or $20 \mathrm{mg}) .{ }^{112,122}$ Suvorexant is a schedule IV controlled substance.

In 2019, lemborexant became the second DORA to receive approval in the United States for the treatment of insomnia characterized by difficulties with sleep onset and/or sleep maintenance in adults. ${ }^{131}$ Similar to suvorexant, lemborexant is a schedule IV controlled substance. Lemborexant is also approved in multiple countries, including Japan and Canada, for the treatment of insomnia. ${ }^{101}$ In a Phase 2, multicenter, randomized, double-blind, placebo-controlled, Bayesian, adaptive, parallel-group study of lemborexant $(1,2.5,5,10$, 15 , or $25 \mathrm{mg}$ ) for 15 nights, patients ( $\geq 18$ years of age) receiving lemborexant at doses $\geq 5 \mathrm{mg}$ had significantly greater improvements in sleep efficiency (SE), subjective SE (sSE), LPS, and subjective SOL versus placebo. ${ }^{132}$ In a randomized, double-blind, parallel-group, placebo-controlled and activecomparator, phase 3 study in females ( $\geq 55$ years of age) and males ( $\geq 65$ years of age) with insomnia disorder, lemborexant ( $5 \mathrm{mg}$ or $10 \mathrm{mg}$ ) demonstrated statistically significantly greater improvements on objective (PSG-based) measures of sleep onset and sleep maintenance compared with placebo and with zolpidem tartrate extended release $(6.25 \mathrm{mg})$ as assessed at 1 month. ${ }^{118}$ Additionally, changes from baseline in subjective (sleep diary-based) SOL were greater and statistically significant with lemborexant compared with placebo and with zolpidem as assessed at the end of 1 month. ${ }^{118}$ Similarly, in a 12-month, randomized, double-blind, parallelgroup, phase 3 study, which was placebo-controlled for the first 6 months, patients ( $\geq 18$ years of age) treated with lemborexant (5 mg or $10 \mathrm{mg}$ ) had significantly greater decreases from baseline in the primary endpoint of subjective SOL compared with placebo-treated patients as assessed at the end of 6 months. ${ }^{133}$ Lemborexant also demonstrated significant benefit on sWASO, sSE, sTST, and quality of sleep compared with placebo at the end of the 6-month placebo-controlled period. ${ }^{133}$ Taken together, these results indicated lemborexant exhibits efficacy that is sustained long term.

In both phase 3 clinical trials of lemborexant, the rate of serious treatment-emergent adverse events (TEAEs) was low and no deaths occurred; lemborexant was well tolerated, with most TEAEs rated as mild or moderate in severity. ${ }^{118,133}$ Overall, the most prominent adverse event was somnolence. Similarly, in an analysis of the pharmacokinetic, pharmacodynamic, and safety data from three double-blind, placebo-controlled Phase 1 studies, lemborexant was well tolerated with no evidence of clinically relevant next-morning residual sleepiness. ${ }^{134}$ Overall benefit-to-risk ratio for lemborexant treatment is favorable, as measured by number needed to treat, number needed to harm, and likelihood to be helped or harmed. ${ }^{135}$

Lemborexant was assessed in otherwise healthy adult and elderly participants with mild OSA. ${ }^{136}$ In this phase 1 , randomized, double-blind, placebo-controlled, two-period crossover study, there were no significant differences on measures of respiratory safety including the apnea-hypopnea index and peripheral oxygen saturation for lemborexant $10 \mathrm{mg}$ versus placebo. ${ }^{136}$

In an analysis of nine clinical studies conducted during the clinical development program of lemborexant, which included assessments of next-morning or across-the-day residual medication effects, lemborexant did not negatively impact next-day functioning in healthy individuals or patients with insomnia. ${ }^{137}$ Lemborexant treatment was associated with significantly greater alertness for up to 6 months versus placebo as determined by next-morning sleep diary ratings. ${ }^{137}$ In addition, whereas zolpidem differed from placebo on multiple measures of the Cognitive Performance Assessment Battery, power of attention was 
the only measure that found significantly decreased performance with lemborexant compared with placebo, and only in one of two studies. ${ }^{137}$ Similarly, lemborexant treatment was also not associated with statistically significant or clinically meaningful next-day impairment in a randomized, double-blind, double-dummy, placebo- and active-controlled, four-period, incomplete crossover study conducted in healthy volunteers to determine effects on driving performance during a standardized highway driving test in normal traffic. ${ }^{138}$ However, while there were no stopped drives during the lemborexant conditions, driving ability was impaired in 2 of the 32 participants receiving lemborexant $10 \mathrm{mg}$, and the product label recommends that patients who take the 10-mg dose should be advised about the possibility of next-morning driving impairment due to individual variation in lemborexant sensitivity; of note, the recommended starting dose of lemborexant is $5 \mathrm{mg} .{ }^{139}$ The effects of lemborexant, zolpidem, and placebo on auditory awakening threshold and postural stability in the middle of the night and upon morning awakening were assessed in healthy females $(\geq 55$ years of age) and males ( $\geq 65$ years of age). ${ }^{140}$ Neither lemborexant nor zolpidem impaired the ability of participants to awaken to auditory signals in the middle of the night (4 hours post-dose). ${ }^{140}$ While both lemborexant and zolpidem induced significantly more postural instability than placebo in the middle of the night (4 hours post-dose), lemborexant was associated with significantly less postural instability than zolpidem. ${ }^{140}$ In the morning ( 8 hours postdose), postural instability was observed with zolpidem compared with placebo, but not for lemborexant compared with placebo. ${ }^{140}$ An open-label pilot study (NCT04009577, E2006-A001-312) has been carried out to evaluate prespecified dosing approaches for direct transition from zolpidem to lemborexant. ${ }^{141,142}$ The primary endpoint of the study, which was recently completed, is the proportion of patients with insomnia who successfully transition from intermittent or frequent zolpidem use to lemborexant $5 \mathrm{mg}$ or $10 \mathrm{mg}$ after 2 weeks of treatment. ${ }^{142}$ Following the 2-week titration period, 43 out of 53 subjects $(81.1 \%)$ transitioned to lemborexant.

Daridorexant is a DORA that is in development for the treatment of insomnia; the New Drug Application was submitted in January 2021. Recently, results from two phase 2 trials evaluating the efficacy and safety of daridorexant were published. ${ }^{143,144}$ One trial was conducted to evaluate the dose-response relationship of daily daridorexant $(5,10$, 25 , or $50 \mathrm{mg}$ ) for 30 days compared with oral placebo or
$10 \mathrm{mg}$ zolpidem in adults ( $\leq 64$ years of age) with insomnia disorder. ${ }^{143}$ Daridorexant induced a dose-dependent reduction in WASO and subjective latency to sleep onset with no clinically relevant treatment-related serious adverse events and a low rate of discontinuation due to adverse events. ${ }^{143}$ The second trial was conducted to assess the dose-response of daridorexant $(5,10,25$, and $50 \mathrm{mg})$ versus placebo in elderly patients with insomnia. ${ }^{144}$ Daridorexant-treated patients had statistically significant, dose-dependent improvements in WASO and LPS, with similar rates of TEAEs as those patients treated with placebo. ${ }^{144}$

The phase 2 trials supported continued development of daridorexant to phase 3. Positive topline results of the first pivotal trial, which was conducted to evaluate daridorexant 25 and $50 \mathrm{mg}$ in adult and elderly patients with insomnia, were announced in April 2020. ${ }^{145}$ Daridorexant treatment improved both objective and subjective sleep parameters and daytime performance over 3 months without evidence of residual effects, rebound insomnia, or withdrawal symptoms after discontinuation. ${ }^{145}$ In July 2020, topline results from the second phase 3 study, which examined daridorexant 10 and $25 \mathrm{mg}$ in adult and elderly patients with insomnia were announced. ${ }^{146}$ These results were in agreement with the previous findings and demonstrated improvements on objective and subjective sleep measures (sleep onset, sleep maintenance, and sTST) with daridorexant treatment. Additionally, positive effects on daytime functioning were observed, with no reports of morning sleepiness or evidence of rebound or withdrawal symptoms. ${ }^{146}$

Almorexant was the first DORA to undergo phase 3 clinical evaluation, but was ultimately discontinued because of safety findings of abnormally elevated liver enzymes. ${ }^{66}$ Other DORAs that had been in clinical development, SB-649868 and filorexant (MK-6096), completed phase 2 trials but have since been discontinued. ${ }^{147,148}$ Seltorexant (JNJ-42847922) is an OX2R antagonist currently in phase 3 clinical development for the treatment of insomnia and major depressive disorder. ${ }^{149}$ A phase $2 \mathrm{~b}$ active- and placebo-controlled study in adult and elderly subjects with insomnia disorder found that seltorexant at 5 , 10 and $20 \mathrm{mg}$ significantly improved LPS versus placebo. ${ }^{150}$ Greater improvement in LPS was also seen with seltorexant $20 \mathrm{mg}$ compared with zolpidem. ${ }^{150}$ Additionally, seltorexant improved LPS and TST, and SE compared with placebo in an exploratory crossover study in subjects with antidepressant-treated major depressive disorder and who have persistent insomnia. ${ }^{151}$ 


\section{Practical Advice for Clinicians Treating} Patients with Pharmacologic Therapies

Abrupt changes in treatment with older-generation hypnotics can lead to rebound insomnia with worsened sleep. ${ }^{152}$ This is of practical concern because a common scenario is that of a person with chronic insomnia whose medication treatment has ceased to be effective because of the development of physiological tolerance. A new medication (such as an orexin receptor antagonist) may be prescribed, but the new intervention may fail if the old hypnotic is abruptly discontinued because there is no cross-tolerance between the older medications (such as BZD and non-BZD hypnotics) and orexin receptor antagonists. The patient may misinterpret this failure as due to inefficacy of the new therapy rather than the result of abrupt discontinuation of the prior medication. A gradual tapering off of the old hypnotic may help to avoid rebound insomnia, particularly when the older agent was taken every night for months or years. ${ }^{152}$ If patients choose to switch medications, health care practitioners should discuss how to manage this change. A practical approach to managing changes in insomnia medication includes providing patients written information about medication discontinuation, including a discussion of change in the subjective experience they may have with the new medication, using stepped care with a tailored approach to the amount of intervention, and adding CBT-I or behavioral therapies, which may help improve the transition during discontinuation of a hypnotic therapy. ${ }^{152,153}$ Additional research is needed to optimize the process of changing therapies, especially when patients are switching classes of pharmacologic treatments.

Because BZDs can depress respiratory drive, they are generally avoided as hypnotics in patients with OSA. Although the safety of orexin-receptor antagonists has been established in patients with mild to moderate OSA, ${ }^{128,136,154}$ further studies characterizing the use of orexin receptor antagonists in insomnia disorder in people with more severe forms of OSA would also help better inform clinical practice.

\section{Conclusions}

Several advances in the nonpharmacologic and pharmacologic treatment options for chronic insomnia have occurred recently. The newest delivery enhancements for CBT-I, such as the stepped-care approach, digital delivery of CBT-I, and the inclusion of mindfulness-based stress reduction as well as the novel approach of forehead cooling, may provide patients with insomnia greater access to and efficacy with nonpharmacologic interventions. In addition, the availability of the new DORA medication class means that more pharmacologic options are available for patients. These new therapies may improve sleep outcomes with fewer TEAEs and less risk of next-morning residual sleepiness or impairments. Additional studies are needed to evaluate the efficacy of combining newly available pharmacologic treatments, such as DORAs, with nonpharmacologic treatments. If patients choose to change classes of therapies from the older pharmacological approaches, health care practitioners need to educate patients to help them manage the transition and avoid rebound insomnia, and thus improve patient satisfaction with their insomnia therapy.

\section{Abbreviations}

AASM, American Academy of Sleep Medicine; ACP, American College of Physicians; APA, American Psychiatric Association; BZD, benzodiazepine; CBT-I, cognitive behavioral therapies for insomnia; DORA, dual orexin receptor antagonist; FDA, US Food and Drug Administration; GABA, $\gamma$-aminobutyric acid; LPS, latency to onset of persistent sleep; MBTI, mindfulness-based therapy for insomnia; OSA, obstructive sleep apnea; OX-A, orexin-A; OX-B, orexin-B; OX1R, orexin receptor type 1; OX2R, orexin receptor type 2; PSG, polysomnography; QOL, quality of life; REM, rapid eye movement; SE, sleep efficiency; SOL, sleep onset latency; SSE, subjective sleep efficiency; sTSO, subjective time to sleep onset; sTST, subjective total sleep time; sWASO, subjective wake after sleep onset; TEAE, treatment-emergent adverse event; WASO, wake after sleep onset.

\section{Acknowledgments}

Medical writing assistance was provided by Christina McManus of Envision Pharma Group. Services provided by Envision Pharma Group complied with international guidelines for Good Publication Practice (GPP3).

\section{Author Contributions}

All authors made a significant contribution to the work reported, whether that is in the conception, execution, acquisition of data, analysis and interpretation, or in all these areas; took part in drafting, revising or critically reviewing the article; gave final approval of the version to be published; have agreed on the journal to which the article has been submitted; and agree to be accountable for all aspects of the work. 


\section{Funding}

Funding for medical writing assistance was provided by Eisai Inc., who was not involved in any aspects of manuscript preparation.

\section{Disclosure}

No payments were received by the authors for the creation of this review. Dr Rosenberg has received grants from Eisai, Idorsia, Merck, and Vanda Pharmaceuticals. In the past 12 months, Dr Citrome has served as a consultant to AbbVie, Acadia, Alkermes, Allergan, Angelini, Astellas, Avanir, Axsome, BioXcel, Boehringer Ingelheim, Cadent Therapeutics, Eisai, Impel, Intra-Cellular Therapies, Janssen, Karuna, Lundbeck, Luye, Lyndra, MedavanteProPhase, Merck, Neurocrine, Noven, Osmotica, Otsuka, Relmada, Sage, Shire, Sunovion, Takeda, Teva, University of Arizona, and one-off ad hoc consulting for individuals/ entities conducting marketing, commercial, or scientific scoping research; served as a speaker for AbbVie, Acadia, Alkermes, Allergan, Angelini, Eisai, Intra-Cellular Therapies, Janssen, Lundbeck, Merck, Neurocrine, Noven, Otsuka, Sage, Shire, Sunovion, Takeda, Teva, and CME activities organized by medical education companies such as Medscape, NACCME, NEI, Vindico, and Universities and Professional Organizations/Societies; held stocks (small number of shares of common stock) in Bristol-Myers Squibb, Eli Lilly, J

$\&$ J, Merck, Pfizer purchased $>10$ years ago; and received royalties from Wiley (Editor-in-Chief, International Journal of Clinical Practice, through end 2019), UpToDate (reviewer), Springer Healthcare (book), Elsevier (Topic Editor, Psychiatry, Clinical Therapeutics). Dr Drake served as a speaker for Harmony Biosciences, Eisai and Jazz Pharmaceuticals and has received research funding and served as a consultant for Eisai, Harmony Biosciences, Jazz Pharmaceuticals, Merck, UpToDate (contributor), Aladdin Dreamer, Fisher-Wallace Laboratories Inc., Axsome Therapeutics, Procter \& Gamble, and Suven Life Sciences.

\section{References}

1. American Academy of Sleep Medicine. International Classification of Sleep Disorders. 3rd ed. American Academy of Sleep Medicine; 2014.

2. Sateia MJ, Buysse DJ, Krystal AD, Neubauer DN, Heald JL. Clinical practice guideline for the pharmacologic treatment of chronic insomnia in adults: an American Academy of Sleep Medicine clinical practice guideline. J Clin Sleep Med. 2017;13(2):307-349. doi:10.5664/ jesm. 6470
3. American Psychiatric Association (APA). Diagnostic and Statistical Manual of Mental Disorders. 5th ed. American Psychiatric Association; 2013.

4. Morin CM, Jarrin DC, Ivers H, Mérette C, LeBlanc M, Savard J. Incidence, persistence, and remission rates of insomnia over 5 years. JAMA Netw Open. 2020;3(11):e2018782. doi:10.1001/ jamanetworkopen.2020.18782

5. Carney CE, Segal ZV, Edinger JD, Krystal AD. A comparison of rates of residual insomnia symptoms following pharmacotherapy or cognitive-behavioral therapy for major depressive disorder. $J \quad$ Clin Psychiatry. 2007;68(2):254-260. doi:10.4088/jcp. v68n0211

6. Nierenberg AA, Keefe BR, Leslie VC, et al. Residual symptoms in depressed patients who respond acutely to fluoxetine. $J$ Clin Psychiatry. 1999;60(4):221-225. doi:10.4088/jcp.v60n0403

7. Fava M, McCall WV, Krystal A, et al. Eszopiclone co-administered with fluoxetine in patients with insomnia coexisting with major depressive disorder. Biol Psychiatry. 2006;59 (11):1052-1060. doi:10.1016/j.biopsych.2006.01.016

8. Manber R, Edinger JD, Gress JL, San Pedro-Salcedo MG, Kuo TF, Kalista T. Cognitive behavioral therapy for insomnia enhances depression outcome in patients with comorbid major depressive disorder and insomnia. Sleep. 2008;31(4):489-495. doi:10.1093/sleep/31.4.489

9. Edinger JD, Arnedt JT, Bertisch SM, et al. Behavioral and psychological treatments for chronic insomnia disorder in adults: an American Academy of Sleep Medicine clinical practice guideline. J Clin Sleep Med. 2021;17(2):255-262. doi:10.5664/jcsm.8986

10. Schutte-Rodin S, Broch L, Buysse D, Dorsey C, Sateia M. Clinical guideline for the evaluation and management of chronic insomnia in adults. J Clin Sleep Med. 2008;4(5):487-504. doi:10.5664/jcsm.27286

11. Bjorøy I, Jørgensen VA, Pallesen S, Bjorvatn B. The prevalence of insomnia subtypes in relation to demographic characteristics, anxiety, depression, alcohol consumption and use of hypnotics. Front Psychol. 2020;11:527. doi:10.3389/fpsyg.2020.00527

12. Hohagen F, Käppler C, Schramm E, Riemann D, Weyerer S, Berger M. Sleep onset insomnia, sleep maintaining insomnia and insomnia with early morning awakening-temporal stability of subtypes in a longitudinal study on general practice attenders. Sleep. 1994;17(6):551-554.

13. Rosenberg RP. Sleep maintenance insomnia: strengths and weaknesses of current pharmacologic therapies. Ann Clin Psychiatry. 2006;18(1):49-56. doi:10.1080/10401230500464711

14. Pillai V, Roth T, Drake CL. The nature of stable insomnia phenotypes. Sleep. 2015;38(1):127-138. doi:10.5665/sleep.4338

15. Vgontzas AN, Fernandez-Mendoza J, Liao D, Bixler EO. Insomnia with objective short sleep duration: the most biologically severe phenotype of the disorder. Sleep Med Rev. 2013;17 (4):241-254. doi:10.1016/j.smrv.2012.09.005

16. Chattu VK, Manzar MD, Kumary S, Burman D, Spence DW, Pandi-Perumal SR. The global problem of insufficient sleep and its serious public health implications. Healthcare. 2018;7(1):1. doi:10.3390/healthcare7010001

17. Bertisch SM, Pollock BD, Mittleman MA, et al. Insomnia with objective short sleep duration and risk of incident cardiovascular disease and all-cause mortality: Sleep Heart Health Study. Sleep. 2018;41(6):zsy047. doi:10.1093/sleep/zsy047

18. Vgontzas AN, Fernandez-Mendoza J. Insomnia with short sleep duration: nosological, diagnostic, and treatment implications. Sleep Med Clin. 2013;8(3):309-322. doi:10.1016/j. jsmc.2013.04.009

19. Vgontzas AN, Liao D, Bixler EO, Chrousos GP, Vela-Bueno A. Insomnia with objective short sleep duration is associated with a high risk for hypertension. Sleep. 2009;32(4):491-497. doi:10.1093/sleep/32.4.491 
20. Gangwisch JE, Malaspina D, Boden-Albala B, Heymsfield SB. Inadequate sleep as a risk factor for obesity: analyses of the NHANES I. Sleep. 2005;28(10):1289-1296. doi:10.1093/sleep/ 28.10 .1289

21. Wu Y, Zhai L, Zhang D. Sleep duration and obesity among adults: a meta-analysis of prospective studies. Sleep Med. 2014;15 (12):1456-1462. doi:10.1016/j.sleep.2014.07.018

22. Taheri S, Lin L, Austin D, Young T, Mignot E. Short sleep duration is associated with reduced leptin, elevated ghrelin, and increased body mass index. PLoS Med. 2004;1(3):e62. doi:10.1371/journal.pmed.0010062

23. Pandi-Perumal SR, Monti JM, Burman D, et al. Clarifying the role of sleep in depression: a narrative review. Psychiatry Res. 2020;291:113239. doi:10.1016/j.psychres.2020.113239

24. Colvonen PJ, Straus LD, Stepnowsky C, McCarthy MJ, Goldstein LA, Norman SB. Recent advancements in treating sleep disorders in co-occurring PTSD. Curr Psychiatry Rep. 2018;20(7):48. doi:10.1007/s11920-018-0916-9

25. Nutt D, Wilson S, Paterson L. Sleep disorders as core symptoms of depression. Dialogues Clin Neurosci. 2008;10(3):329-336.

26. Taylor DJ, Lichstein KL, Durrence HH, Reidel BW, Bush AJ. Epidemiology of insomnia, depression, and anxiety. Sleep. 2005;28(11):1457-1464. doi:10.1093/sleep/28.11.1457

27. McCall WV, Blocker JN, D'Agostino RJ, et al. Insomnia severity is an indicator of suicidal ideation during a depression clinical trial. Sleep Med. 2010;11(9):822-827. doi:10.1016/j.sleep.2010.04.004

28. Cheng P, Kalmbach DA, Tallent G, Joseph CL, Espie CA, Drake CL. Depression prevention via digital cognitive behavioral therapy for insomnia: a randomized controlled trial. Sleep. 2019;42(10):zsz150. doi:10.1093/sleep/zsz150

29. Foley DJ, Monjan AA, Brown SL, Simonsick EM, Wallace RB, Blazer DG. Sleep complaints among elderly persons: an epidemiologic study of three communities. Sleep. 1995;18(6):425-432. doi:10.1093/sleep/18.6.425

30. Taylor DJ, Mallory LJ, Lichstein KL, Durrence HH, Riedel BW, Bush AJ. Comorbidity of chronic insomnia with medical problems. Sleep. 2007;30(2):213-218. doi:10.1093/sleep/30.2.213

31. Ishak WW, Bagot K, Thomas S, et al. Quality of life in patients suffering from insomnia. Innov Clin Neurosci. 2012;9(10):13-26.

32. Daley M, Morin CM, LeBlanc M, Grégoire JP, Savard J. The economic burden of insomnia: direct and indirect costs for individuals with insomnia syndrome, insomnia symptoms, and good sleepers. Sleep. 2009;32(1):55-64.

33. Wade AG. The societal costs of insomnia. Neuropsychiatr Dis Treat. 2010;7:1-18. doi:10.2147/NDT.S15123

34. Léger D, Morin CM, Uchiyama M, Hakimi Z, Cure S, Walsh JK. Chronic insomnia, quality-of-life, and utility scores: comparison with good sleepers in a cross-sectional international survey. Sleep Med. 2012;13(1):43-51. doi:10.1016/j.sleep.2011.03.020

35. RAND Healthcare. 36-item short form survey (SF-36). Available from: https://www.rand.org/health-care/surveys_tools/mos/36item-short-form.html. Accessed October 17, 2020.

36. Olfson M, Wall M, Liu SM, Morin CM, Blanco C. Insomnia and impaired quality of life in the United States. J Clin Psychiatry. 2018;79(5):17m12020. doi:10.4088/JCP.17m12020

37. Bhaskar S, Hemavathy D, Prasad S. Prevalence of chronic insomnia in adult patients and its correlation with medical comorbidities. J Family Med Prim Care. 2016;5(4):780-784. doi:10.4103/2249-4863.201153

38. Gooneratne NS, Tavaria A, Patel N, et al. Perceived effectiveness of diverse sleep treatments in older adults. J Am Geriatr Soc. 2011;59(2):297-303. doi:10.1111/j.1532-5415.2010.03247.x

39. Morin CM, LeBlanc M, Daley M, Gregoire JP, Mérette C. Epidemiology of insomnia: prevalence, self-help treatments, consultations, and determinants of help-seeking behaviors. Sleep Med. 2006;7(2):123-130. doi:10.1016/j.sleep.2005.08.008
40. Bartlett DJ, Marshall NS, Williams A, Grunstein RR. Predictors of primary medical care consultation for sleep disorders. Sleep Med. 2008;9(8):857-864. doi:10.1016/j.sleep.2007.09.002

41. Ancoli-Israel S, Roth T. Characteristics of insomnia in the United States: results of the 1991 National Sleep Foundation Survey. I. Sleep. 1999;22(Suppl 2):S347-S353.

42. Leger D, Poursain B. An international survey of insomnia: under-recognition and under-treatment of a polysymptomatic condition. Curr Med Res Opin. 2005;21(11):1785-1792. doi:10.1185/030079905X65637

43. Spielman AJ, Caruso LS, Glovinsky PB. A behavioral perspective on insomnia treatment. Psychiatr Clin North Am. 1987;10 (4):541-553. doi:10.1016/S0193-953X(18)30532-X

44. Drake CL, Pillai V, Roth T. Stress and sleep reactivity: a prospective investigation of the stress-diathesis model of insomnia. Sleep. 2014;37(8):1295-1304. doi:10.5665/sleep.3916

45. Perlis M, Gehrman PR, Ellis J. The natural history of insomnia: what we know, don't know, and need to know. Sleep Med Res. 2011;2(3):79-88. doi:10.17241/smr.2011.2.3.79

46. Vgontzas AN, Bixler EO, Lin HM, et al. Chronic insomnia is associated with nyctohemeral activation of the hypothalamic-pituitary-adrenal axis: clinical implications. J Clin Endocrinol Metab. 2001;86(8):3787-3794. doi:10.1210/ jcem.86.8.7778

47. Levenson JC, Kay DB, Buysse DJ. The pathophysiology of insomnia. Chest. 2015;147(4):1179-1192. doi:10.1378/chest.141617

48. Koranyi N, Meinhard M, Bublak P, Witte OW, Rupprecht S. Automatic affective responses towards the bed in patients with primary insomnia: evidence for a negativity bias. $J$ Sleep Res. 2018;27(2):215-219. doi:10.1111/jsr.12591

49. Bonnet MH, Arand DL. Insomnia, metabolic rate and sleep restoration. J Intern Med. 2003;254(1):23-31. doi:10.1046/ j.1365-2796.2003.01176.x

50. Nofzinger EA, Buysse DJ, Germain A, Price JC, Miewald JM, Kupfer DJ. Functional neuroimaging evidence for hyperarousal in insomnia. Am $J$ Psychiatry. 2004;161(11):2126-2128. doi:10.1176/appi.ajp.161.11.2126

51. Carney CE, Harris AL, Falco A, Edinger JD. The relation between insomnia symptoms, mood, and rumination about insomnia symptoms. J Clin Sleep Med. 2013;9(6):567-575. doi: $10.5664 /$ jcsm. 2752

52. Carney CE, Harris AL, Moss TG, Edinger JD. Distinguishing rumination from worry in clinical insomnia. Behav Res Ther. 2010;48(6):540-546. doi:10.1016/j.brat.2010.03.004

53. Kalmbach DA, Buysse DJ, Cheng P, Roth T, Yang A, Drake CL. Nocturnal cognitive arousal is associated with objective sleep disturbance and indicators of physiologic hyperarousal in good sleepers and individuals with insomnia disorder. Sleep Med. 2020;71:151-160. doi:10.1016/j.sleep.2019.11.1184

54. Drake CL, Friedman NP, Wright KP Jr, Roth T. Sleep reactivity and insomnia: genetic and environmental influences. Sleep. 2011;34(9):1179-1188. doi:10.5665/SLEEP.1234

55. Brower KJ, Wojnar M, Sliwerska E, Armitage R, Burmeister M. PER3 polymorphism and insomnia severity in alcohol dependence. Sleep. 2012;35(4):571-577. doi:10.5665/sleep.1748

56. Li J, Huang C, Lan Y, Wang Y. A cross-sectional study on the relationships among the polymorphism of period2 gene, work stress, and insomnia. Sleep Breath. 2015;19(4):1399-1406. doi:10.1007/s11325-015-1229-4

57. Lind MJ, Gehrman PR. Genetic pathways to insomnia. Brain Sci. 2016;6(4):64. doi:10.3390/brainsci6040064

58. Utge SJ, Soronen P, Loukola A, et al. Systematic analysis of circadian genes in a population-based sample reveals association of TIMELESS with depression and sleep disturbance. PLoS One. 2010;5(2):e9259. doi:10.1371/journal.pone.0009259 
59. Harvey CJ, Gehrman P, Espie CA. Who is predisposed to insomnia: a review of familial aggregation, stress-reactivity, personality and coping style. Sleep Med Rev. 2014;18(3):237-247. doi:10.1016/j.smrv.2013.11.004

60. Saper CB, Scammell TE, Lu J. Hypothalamic regulation of sleep and circadian rhythms. Nature. 2005;437(7063):1257-1263. doi: 10.1038 /nature04284

61. Chieffi S, Carotenuto M, Monda V, et al. Orexin system: the key for a healthy life. Front Physiol. 2017;8:357. doi:10.3389/ fphys.2017.00357

62. Scammell TE, Arrigoni E, Lipton JO. Neural circuitry of wakefulness and sleep. Neuron. 2017;93(4):747-765. doi:10.1016/j. neuron.2017.01.014

63. Barson JR, Leibowitz SF. Orexin/hypocretin system: role in food and drug overconsumption. Int Rev Neurobiol. 2017;136:199-237. doi:10.1016/bs.irn.2017.06.006

64. Willie JT, Chemelli RM, Sinton CM, et al. Distinct narcolepsy syndromes in orexin receptor- 2 and orexin null mice: molecular genetic dissection of Non-REM and REM sleep regulatory processes. Neuron. 2003;38(5):715-730. doi:10.1016/s08966273(03)00330-1

65. Beuckmann CT, Suzuki M, Ueno T, Nagaoka K, Arai T, Higashiyama $\mathrm{H}$. In vitro and in silico characterization of lemborexant (E2006), a novel dual orexin receptor antagonist. $J$ Pharmacol Exp Ther. 2017;362(2):287-295. doi:10.1124/ jpet.117.241422

66. Janto K, Prichard JR, Pusalavidyasagar S. An update on dual orexin receptor antagonists and their potential role in insomnia therapeutics. J Clin Sleep Med. 2018;14(8):1399-1408. doi: $10.5664 / \mathrm{jcsm} .7282$

67. Qaseem A, Kansagara D, Forciea MA, Cooke M, Denberg TD. Clinical Guidelines Committee of the American College of Physicians. Management of chronic insomnia disorder in adults: a clinical practice guideline from the American College of Physicians. Ann Intern Med. 2016;165(2):125-133. doi:10.7326/ M15-2175

68. Edinger JD, Arnedt JT, Bertisch SM, et al. Behavioral and psychological treatments for chronic insomnia disorder in adults: an American Academy of Sleep Medicine systematic review, meta-analysis, and GRADE assessment. J Clin Sleep Med. 2021;17(2):263-298. doi:10.5664/jcsm.8988

69. Davidson JR, Dickson C, Han H. Cognitive behavioural treatment for insomnia in primary care: a systematic review of sleep outcomes. $B r \quad J$ Gen Pract. 2019;69(686):e657-e664. doi:10.3399/bjgp19X705065

70. Morgenthaler T, Kramer M, Alessi C, et al. Practice parameters for the psychological and behavioral treatment of insomnia: an update. An American Academy of Sleep Medicine report. Sleep. 2006;29(11):1415-1419. doi:10.1093/sleep/29.11.1415

71. Thakral M, Von Korff M, McCurry SM, Morin CM, Vitiello MV Changes in dysfunctional beliefs about sleep after cognitive behavioral therapy for insomnia: a systematic literature review and meta-analysis. Sleep Med Rev. 2020;49:101230. doi:10.1016/j. smrv.2019.101230

72. Harvey AG, Bélanger L, Talbot L, et al. Comparative efficacy of behavior therapy, cognitive therapy, and cognitive behavior therapy for chronic insomnia: a randomized controlled trial. $J$ Consult Clin Psychol. 2014;82(4):670-683. doi:10.1037/a0036606

73. Smith MT, Jungquist C, Perlis ML, Posner D. Cognitive Behavioral Treatment of Insomnia: A Session-By-Session Guide. Germany: Springer; 2005.

74. Carney CE, Posner D. Cognitive Behavior Therapy for Insomnia in Those with Depression: A Guide for Clinicians. Routledge/ Taylor \& Francis Group; 2016.
75. Perlis ML, Pigeon WR, Grandner MA, et al. Why Treat Insomnia? $J$ Prim Care Community Health. 2021;12:21501327211014084. doi:10.1177/21501327211014084

76. Buysse DJ, Germain A, Moul DE, et al. Efficacy of brief behavioral treatment for chronic insomnia in older adults. Arch Intern Med. 2011;171(10):887-895. doi:10.1001/archinternmed.2010. 535

77. Epstein DR, Sidani S, Bootzin RR, Belyea MJ. Dismantling multicomponent behavioral treatment for insomnia in older adults: a randomized controlled trial. Sleep. 2012;35 (6):797-805. doi:10.5665/sleep. 1878

78. Morin CM, Vallières A, Guay B, et al. Cognitive behavioral therapy, singly and combined with medication, for persistent insomnia: a randomized controlled trial. JAMA. 2009;301 (19):2005-2015. doi:10.1001/jama.2009.682

79. Wu JQ, Appleman ER, Salazar RD, Ong JC. Cognitive behavioral therapy for insomnia comorbid with psychiatric and medical conditions: a meta-analysis. JAMA Intern Med. 2015;175 (9):1461-1472. doi:10.1001/jamainternmed.2015.3006

80. Koffel E, Bramoweth AD, Ulmer CS. Increasing access to and utilization of cognitive behavioral therapy for insomnia (CBT-I): a narrative review. $J$ Gen Intern Med. 2018;33(6):955-962. doi:10.1007/s11606-018-4390-1

81. Perlis M, Shaw P, Cano G, Espie C. Models of insomnia. In: Kryger MH, Roth T, Dement WC, editors. Principles and Practice of Sleep Medicine. Saunders Elsevier; 2010:850-865.

82. Okajima I, Nakajima S, Ochi M, Inoue Y. Reducing dysfunctional beliefs about sleep does not significantly improve insomnia in cognitive behavioral therapy. PLoS One. 2014;9(7):e102565. doi:10.1371/journal.pone.0102565

83. Lancee J, van Straten A, Morina N, Kaldo V, Kamphuis JH. Guided online or face-to-face cognitive behavioral treatment for insomnia: a randomized wait-list controlled trial. Sleep. 2016;39 (1):183-191. doi:10.5665/sleep.5344

84. Conroy DA, Ebben MR. Referral practices for cognitive behavioral therapy for insomnia: a survey study. Behav Neurol. 2015;2015(2015):819402. doi:10.1155/2015/819402

85. Espie CA. "Stepped care": a health technology solution for delivering cognitive behavioral therapy as a first line insomnia treatment. Sleep. 2009;32(12):1549-1558. doi:10.1093/sleep/ 32.12.1549

86. Soh HL, Ho RC, Ho CS, Tam WW. Efficacy of digital cognitive behavioural therapy for insomnia: a meta-analysis of randomised controlled trials. Sleep Med. 2020;75:315-325. doi:10.1016/j. sleep.2020.08.020

87. Kuhn E, Weiss BJ, Taylor KL, et al. CBT-I coach: a description and clinician perceptions of a mobile app for cognitive behavioral therapy for insomnia. J Clin Sleep Med. 2016;12(4):597-606. doi: $10.5664 /$ jcsm. 5700

88. Ong JC, Shapiro SL, Manber R. Combining mindfulness meditation with cognitive-behavior therapy for insomnia: a treatment-development study. Behav Ther. 2008;39(2):171-182. doi:10.1016/j.beth.2007.07.002

89. Ong J, Sholtes D. A mindfulness-based approach to the treatment of insomnia. $J$ Clin Psychol. 2010;66(11):1175-1184. doi:10.1002/jclp.20736

90. Ong JC, Shapiro SL, Manber R. Mindfulness meditation and cognitive behavioral therapy for insomnia: a naturalistic 12-month follow-up. Explore. 2009;5(1):30-36. doi:10.1016/j. explore.2008.10.004

91. Nowakowski S, Meers JM. Cognitive behavioral therapy for insomnia and women's health: sex as a biological variable. Sleep Med Clin. 2019;14(2):185-197. doi:10.1016/j. jsmc.2019.01.002 
92. Sedov ID, Goodman SH, Tomfohr-Madsen LM. Insomnia treatment preferences during pregnancy. J Obstet Gynecol Neonatal Nurs. 2017;46(3):e95-e104. doi:10.1016/j. jogn.2017.01.005

93. Manber R, Bei B, Simpson N, et al. Cognitive behavioral therapy for prenatal insomnia: a randomized controlled trial. Obstet Gynecol. 2019;133(5):911-919.

doi:10.1097/ AOG.0000000000003216

94. Kalmbach DA, Cheng P, O'Brien LM, et al. A randomized controlled trial of digital cognitive behavioral therapy for insomnia in pregnant women. Sleep Med. 2020;72:82-92. doi:10.1016/j. sleep.2020.03.016

95. Drake CL, Kalmbach DA, Arnedt JT, et al. Treating chronic insomnia in postmenopausal women: a randomized clinical trial comparing cognitive-behavioral therapy for insomnia, sleep restriction therapy, and sleep hygiene education. Sleep. 2019;42 (2):zsy217. doi:10.1093/sleep/zsy217

96. Kalmbach DA, Cheng P, Arnedt JT, et al. Improving daytime functioning, work performance, and quality of life in postmenopausal women with insomnia: comparing cognitive behavioral therapy for insomnia, sleep restriction therapy, and sleep hygiene education. J Clin Sleep Med. 2019;15(7):999-1010. doi:10.5664/ jcsm.7882

97. Kalmbach DA, Cheng P, Arnedt JT, et al. Treating insomnia improves depression, maladaptive thinking, and hyperarousal in postmenopausal women: comparing cognitive-behavioral therapy for insomnia (CBTI), sleep restriction therapy, and sleep hygiene education. Sleep Med. 2019;55:124-134. doi:10.1016/j. sleep.2018.11.019

98. Roth T, Mayleben D, Feldman N, Lankford A, Grant T, Nofzinger E. A novel forehead temperature-regulating device for insomnia: a randomized clinical trial. Sleep. 2018;41(5): zsy045. doi:10.1093/sleep/zsy045

99. Mysliwiec V, Neylan TC, Chiappetta L, Nofzinger EA. Effects of a forehead cooling device in veterans with chronic insomnia disorder and co-morbid medical and psychiatric conditions: a pilot study. Sleep Breath. 2021;25(1):441-448. doi:10.1007/ s11325-020-02126-w

100. Eisai Inc. U.S. FDA Approves Eisai's Dayvigo (lemborexant) for treatment of insomnia in adult patients [press release]. Available from: https://www.eisai.com/news/2019/news201993.html. Accessed January 31, 2021.

101. Scott LJ. Lemborexant: first approval. Drugs. 2020;80 (4):425-432. doi:10.1007/s40265-020-01276-1

102. Fick DM, Semla TP, Steinman M, et al. American Geriatrics Society 2019 updated AGS Beers Criteria ${ }^{\circledR}$ for potentially inappropriate medication use in older adults. J Am Geriatr Soc. 2019;67(4):674-694. doi:10.1111/jgs. 15767

103. Colrain IM, Nicholas CL, Baker FC. Alcohol and the sleeping brain. Handb Clin Neurol. 2014;125:415-431. doi:10.1016/B9780-444-62619-6.00024-0

104. Hassinger AB, Bletnisky N, Dudekula R, El-Solh AA. Selecting a pharmacotherapy regimen for patients with chronic insomnia. Expert Opin Pharmacother. 2020;21(9):1035-1043. doi:10.1080/ 14656566.2020.1743265

105. Roehrs T, Roth T. Drug-related sleep stage changes: functional significance and clinical relevance. Sleep Med Clin. 2010;5 (4):559-570. doi:10.1016/j.jsmc.2010.08.002

106. Krystal AD, Erman M, Zammit GK, Soubrane C, Roth T; ZOLONG Study Group. Long-term efficacy and safety of zolpidem extended-release $12.5 \mathrm{mg}$, administered 3 to 7 nights per week for 24 weeks, in patients with chronic primary insomnia: a 6-month, randomized, double-blind, placebo-controlled, parallel-group, multicenter study. Sleep. 2008;31(1):79-90. doi:10.1093/sleep/31.1.79
107. Wisden W, Yu X, Franks NP. GABA receptors and the pharmacology of sleep. Handb Exp Pharmacol. 2019;253:279-304. doi:10.1007/164_2017_56

108. Mitchell HA, Weinshenker D. Good night and good luck: norepinephrine in sleep pharmacology. Biochem Pharmacol. 2010;79 (6):801-809. doi:10.1016/j.bcp.2009.10.004

109. US Food and Drug Administration. FDA adds boxed warning for risk of serious injuries caused by sleepwalking with certain prescription insomnia medicines. Available from: https://www.fda. gov/drugs/drug-safety-and-availability/fda-adds-boxed-warningrisk-serious-injuries-caused-sleepwalking-certain-prescriptioninsomnia. Accessed January 31, 2020.

110. Gotter AL, Winrow CJ, Brunner J, et al. The duration of sleep promoting efficacy by dual orexin receptor antagonists is dependent upon receptor occupancy threshold. BMC Neurosci. 2013;14:90. doi:10.1186/1471-2202-14-90

111. Iwakawa S, Kanmura Y, Kuwaki T. Orexin receptor blockade-induced sleep preserves the ability to wake in the presence of threat in mice. Front Behav Neurosci. 2019;12:327. doi:10.3389/fnbeh.2018.00327

112. Rhyne DN, Anderson SL. Suvorexant in insomnia: efficacy, safety and place in therapy. Ther Adv Drug Saf. 2015;6 (5):189-195. doi:10.1177/2042098615595359

113. Clark JW, Brian ML, Drummond SPA, Hoyer D, Jacobson LH. Effects of orexin receptor antagonism on human sleep architecture: a systematic review. Sleep Med Rev. 2020;53:101332. doi:10.1016/j.smrv.2020.101332

114. Snyder E, Ma J, Svetnik V, et al. Effects of suvorexant on sleep architecture and power spectral profile in patients with insomnia: analysis of pooled phase 3 data. Sleep Med. 2016;19:93-100. doi:10.1016/j.sleep.2015.10.007

115. Moline M, Zammit G, Cheng J, Perdomo C, Kumar D, Mayleben D. Comparison of the effect of lemborexant with placebo and zolpidem tartrate extended release on sleep architecture in older adults with insomnia disorder. J Clin Sleep Med. 2021;17(6):1167-1174. doi:10.5664/jcsm.9150

116. Herring WJ, Connor KM, Ivgy-May N, et al. Suvorexant in patients with insomnia: results from two 3-month randomized controlled clinical trials. Biol Psychiatry. 2016;79(2):136-148. doi:10.1016/j.biopsych.2014.10.003

117. Michelson D, Snyder E, Paradis E, et al. Safety and efficacy of suvorexant during 1-year treatment of insomnia with subsequent abrupt treatment discontinuation: a phase 3 randomised, double-blind, placebo-controlled trial. Lancet Neurol. 2014;13(5):461-471. doi:10.1016/S1474-4422(14)70053-5

118. Rosenberg R, Murphy P, Zammit G, et al. Comparison of lemborexant with placebo and zolpidem tartrate extended release for the treatment of older adults with insomnia disorder: a phase 3 randomized clinical trial. JAMA Netw Open. 2019;2(12): e1918254. doi:10.1001/jamanetworkopen.2019.18254

119. Neubauer DN. Lemborexant for insomnia: new agent promotes sleep by suppressing the wake drive supported by the orexin system. Curr Psychiatry. 2020;19(11):43.

120. Kaushik MK, Aritake K, Cherasse Y, et al. Induction of narcolepsy-like symptoms by orexin receptor antagonists in mice. Sleep. 2021. doi:10.1093/sleep/zsab043

121. Lee-Iannotti JK, Parish JM. Suvorexant: a promising, novel treatment for insomnia. Neuropsychiatr Dis Treat. 2016;12:491-495. doi:10.2147/NDT.S31495

122. Belsomra (Suvorexant) Tablets [Prescribing Information]. Whitehouse Station, NJ: Merck \& Co. Inc; 2020.

123. Health Canada. Regulatory decision summary - Belsomra Health Canada. Available from: https://hpr-rps.hres.ca/regcontent/regulatory-decision-summary-detail.php?linkID= RDS00475. Accessed February 6, 2020. 
124. Therapeutic Goods Administration. AusPAR Belsomra Suvorexant Merck Sharp and Dohme Australia Pty Ltd PM-2013-00325-1-1 [internet]. Available from: https://www.tga.gov.au/sites/default/ files/auspar-suvorexant-150411.pdf. Accessed January 12, 2021.

125. Herring WJ, Ceesay P, Snyder E, et al. Polysomnographic assessment of suvorexant in patients with probable Alzheimer's disease dementia and insomnia: a randomized trial. Alzheimers Dement. 2020;16(3):541-551. doi:10.1002/alz.12035

126. Herring WJ, Connor KM, Snyder E, et al. Suvorexant in patients with insomnia: pooled analyses of three-month data from phase-3 randomized controlled clinical trials. $J$ Clin Sleep Med. 2016;12:1215-1225. doi:10.5664/jcsm.6116

127. Citrome L. Suvorexant for insomnia: a systematic review of the efficacy and safety profile for this newly approved hypnotic what is the number needed to treat, number needed to harm and likelihood to be helped or harmed? Int J Clin Pract. 2014;68 (12):1429-1441. doi:10.1111/ijcp.12568

128. Sun H, Palcza J, Card D, et al. Effects of suvorexant, an orexin receptor antagonist, on respiration during sleep in patients with obstructive sleep apnea. J Clin Sleep Med. 2016;12(1):9-17. doi:10.5664/jcsm.5382

129. Vermeeren A, Sun H, Vuurman EFPM, et al. On-the-road driving performance the morning after bedtime use of suvorexant 20 and $40 \mathrm{mg}$ : a study in non-elderly healthy volunteers. Sleep. 2015;38 (11):1803-1813. doi:10.5665/sleep.5168

130. Vermeeren A, Vets E, Vuurman EFPM, et al. On-the-road driving performance the morning after bedtime use of suvorexant 15 and $30 \mathrm{mg}$ in healthy elderly. Psychopharmacology. 2016;233:3341-3351. doi:10.1007/s00213-016-4375-x

131. Dayvigo (Lemborexant) Tablets [Package Insert]. Woodcliff Lake, NJ: Eisai Inc; 2019.

132. Murphy P, Moline M, Mayleben D, et al. Lemborexant, a dual orexin receptor antagonist (DORA) for the treatment of insomnia disorder: results from a Bayesian, adaptive, randomized, double-blind, placebo-controlled study. J Clin Sleep Med. 2017;13(11):1289-1299. doi:10.5664/jcsm.6800

133. Kärppä M, Yardley J, Pinner K, et al. Long-term efficacy and tolerability of lemborexant compared with placebo in adults with insomnia disorder: results from the phase 3 randomized clinical trial SUNRISE 2. Sleep. 2020;43(9):zsaa123. doi:10.1093/sleep/ zsaa123

134. Landry I, Nakai K, Ferry J, et al. Pharmacokinetics, pharmacodynamics, and safety of the dual orexin receptor antagonist lemborexant: findings from single-dose and multiple-ascending-dose phase 1 studies in healthy adults. Clin Pharmacol Drug Dev. 2021;10(2):153-165. doi:10.1002/cpdd.817

135. Citrome L, Juday T, Frech F, Atkins N. Lemborexant for the treatment of insomnia: direct and indirect comparisons with other hypnotics using number needed to treat, number needed to harm, and likelihood to be helped or harmed. J Clin Psychiatry. 2021;82:20m13795. doi:10.4088/JCP.20m13795

136. Cheng JY, Filippov G, Moline M, Zammit GK, Bsharat M, Hall N. Respiratory safety of lemborexant in healthy adult and elderly subjects with mild obstructive sleep apnea: a randomized, double-blind, placebo-controlled, crossover study. J Sleep Res. 2020;29(4):e13021. doi:10.1111/jsr.13021

137. Moline M, Zammit G, Yardley J, et al. Lack of residual morning effects of lemborexant treatment for insomnia: summary of findings across 9 clinical trials. Postgrad Med. 2021;133(1):71-81. doi:10.1080/00325481.2020.1823724

138. Vermeeren A, Jongen S, Murphy P, et al. On-the-road driving performance the morning after bedtime administration of lemborexant in healthy adult and elderly volunteers. Sleep. 2019;42(4): zsy260. doi:10.1093/sleep/zsy260
139. Center for Drug Evaluation and Research. NDA 212028 multi-disciplinary review and evaluation. Available from: https://www.accessdata.fda.gov/drugsatfda_docs/nda/2019/ 212028Orig1s000MultidisciplineR.pdf. Accessed January 12, 2021.

140. Murphy P, Kumar D, Zammit G, Rosenberg R, Moline M. Safety of lemborexant versus placebo and zolpidem: effects on auditory awakening threshold, postural stability, and cognitive performance in healthy older participants in the middle of the night and upon morning awakening. J Clin Sleep Med. 2020;16 (5):765-773. doi:10.5664/jcsm.8294

141. Ahmad M, Malhotra M, Amchin J, Kumar D, Perdomo C, Moline M. Characteristics of insomnia subjects screened for transitioning from zolpidem tartrate to lemborexant in a multicenter pilot study [abstract 0477]. Sleep. 2020;43(Suppl 1):A183. doi:10.1093/sleep/zsaa056.474

142. Rosenberg R, Amchin J, Kumar D, Perdomo C, Moline M, Malhotra M. A multicenter pilot study to evaluate next-dose transition from zolpidem to lemborexant for the treatment of insomnia [abstract 0478]. Sleep. 2020;43(Suppl 1):A183. doi:10.1093/sleep/zsaa056.475

143. Dauvilliers Y, Zammit G, Fietze I, et al. Daridorexant, a new dual orexin receptor antagonist to treat insomnia disorder. Ann Neurol. 2020;87(3):347-356. doi:10.1002/ana.25680

144. Zammit G, Dauvilliers Y, Pain S, Sebök Kinter D, Mansour Y, Kunz D. Daridorexant, a new dual orexin receptor antagonist, in elderly subjects with insomnia disorder. Neurology. 2020;94(21):e2222-e2232. doi:10.1212/WNL.0000000 000009475

145. Idorsia Pharmaceuticals Ltd. Idorsia announces positive results in the first Phase 3 study of daridorexant with improved overall sleep and daytime performance of patients with insomnia [press release]. Available from: https://www.idorsia.com/media/newsdetails?newsId=2284972. Accessed February 22, 2021.

146. Idorsia Pharmaceuticals Ltd. Idorsia announces positive results in the second Phase 3 study of daridorexant [press release]. Available from: https://www.idorsia.com/investors/news-andevents/media-release-details?newsId=2329316. Accessed February 22, 2021.

147. Bettica P, Squassante L, Groeger JA, Gennery B, WinskySommerer R, Dijk DJ. Differential effects of a dual orexin receptor antagonist (SB-649868) and zolpidem on sleep initiation and consolidation, SWS, REM sleep, and EEG power spectra in a model of situational insomnia. Neuropsychopharmacology. 2012;37(5):1224-1233. doi:10.1038/npp.2011.310

148. Connor KM, Mahoney E, Jackson S, et al. A Phase II dose-ranging study evaluating the efficacy and safety of the orexin receptor antagonist filorexant (MK-6096) in patients with primary insomnia. Int $J$ Neuropsychopharmacol. 2016;19(8): pyw022. doi:10.1093/ijnp/pyw022

149. Recourt K, de Boer P, Zuiker R, et al. The selective orexin-2 antagonist seltorexant (JNJ-42847922/MIN-202) shows antidepressant and sleep-promoting effects in patients with major depressive disorder. Transl Psychiatry. 2019;9(1):216. doi:10.1038/s41398-019-0553-Z

150. Savitz A, Saoud JB. Efficacy and safety of seltorexant in insomnia disorder. Sleep. 2020;43(Suppl 1):A193. doi:10.1093/sleep/ zsaa056.501

151. Brooks S, Jacobs GE, de Boer P, et al. The selective orexin-2 receptor antagonist seltorexant improves sleep: an exploratory double-blind, placebo controlled, crossover study in antidepressant-treated major depressive disorder patients with persistent insomnia. J Psychopharmacol. 2019;33(2):202-209. doi:10.1177/0269881118822258 
152. Hintze JP, Edinger JD. Hypnotic discontinuation in chronic insomnia. Sleep Med Clin. 2020;15(2):147-154. doi:10.1016/j. jsmc.2020.02.003

153. Bélanger L, Belleville G, Morin C. Management of hypnotic discontinuation in chronic insomnia. Sleep Med Clin. 2009;4 (4):583-592. doi:10.1016/j.jsmc.2009.07.011

154. Boof ML, Dingemanse J, Lederer K, Fietze I, Ufer M. Effect of the new dual orexin receptor antagonist daridorexant on nighttime respiratory function and sleep in patients with mild and moderate obstructive sleep apnea. Sleep. 2021;44(6):zsaa275. doi:10.1093/ sleep/zsaa275

155. Irish LA, Kline CE, Gunn HE, Buysse DJ, Hall MH. The role of sleep hygiene in promoting public health: a review of empirical evidence. Sleep Med Rev. 2015;22:23-36. doi:10.1016/j. smrv.2014.10.001
156. Centers for Disease Control and Prevention. Tips for better sleep. Available from: https://www.cdc.gov/sleep/about_sleep/sleep_ hygiene.html. Accessed January 13, 2021.

157. Idorsia Pharmaceuticals Ltd. Development pipeline. Available from: https://www.idorsia.com/investors/our-equity-story/develop ment-pipeline. Accessed February 22, 2021.

158. Muehlan C, Brooks S, Zuiker R, van Gerven J, Dingemanse J. Multiple-dose clinical pharmacology of ACT-541468, a novel dual orexin receptor antagonist, following repeated-dose morning and evening administration. Eur Neuropsychopharmacol. 2019;29(7):847-857. doi:10.1016/j. euroneuro.2019.05.009

\section{Publish your work in this journal}

Neuropsychiatric Disease and Treatment is an international, peerreviewed journal of clinical therapeutics and pharmacology focusing on concise rapid reporting of clinical or pre-clinical studies on a range of neuropsychiatric and neurological disorders. This journal is indexed on PubMed Central, the 'PsycINFO' database and CAS, and is the official journal of The International Neuropsychiatric Association (INA). The manuscript management system is completely online and includes a very quick and fair peer-review system, which is all easy to use. Visit http://www.dovepress.com/testimonials.php to read real quotes from published authors. 